\title{
Common Variable Immunodeficiency and Other Immunodeficiency Syndromes in Bronchiectasis
}

\author{
Pamela J. McShane, MD ${ }^{1}$ \\ 1 Section of Pulmonary and Critical Care Medicine, University of Texas \\ Health Science Center at Tyler, Tyler, Texas \\ Semin Respir Crit Care Med 2021;42:525-536.
}

\author{
Address for correspondence Pamela J. McShane, MD, Section of \\ Pulmonary and Critical Care Medicine, University of Texas Health \\ Science Center at Tyler, Hwy 271, Tyler, TX 11937 \\ (e-mail: pamela.mcshane@uthct.edu).
}

\begin{abstract}
Keywords

- common variable immunodeficiency disorders

- bronchiectasis

- primary immunodeficiency

- secondary immunodeficiency

- pulmonary disease

Immunodeficiency represents a vast number of diseases and syndromes. Both primary and secondary forms of immunodeficiency are important contributors to the development of bronchiectasis. Primary immune deficiencies, in particular, are increasingly identified and defined as contributors. Specific immune deficiencies that are closely associated with bronchiectasis and as discussed in this article are common variable immunodeficiency, specific antibody deficiency, immunodeficiencies involving immunoglobulin E, DOCK8 immunodeficiency, phosphoglucomutase 3 deficiency, activated phosphoinositide 3kinase delta syndrome, and X-linked agammaglobulinemia. Each of these primary immune deficiencies has unique nuances. Vigilance for these unique signs and symptoms is likely to improve recognition of specific immunodeficiency in the idiopathic bronchiectasis patient. Secondary forms of immunodeficiency occur as a result of a separate disease process. Graft versus host disease, malignancy, and human immunodeficiency virus are three classic examples discussed in this article. An awareness of the potential for these disease settings to lead to bronchiectasis is necessary to optimize patient care. With understanding and mindfulness toward the intricate relationship between bronchiectasis and immunodeficiency, there is an opportunity to elucidate pathophysiologic underpinnings between these two syndromes.
\end{abstract}

With increased attention directed toward bronchiectasis in recent years, there has been a recognition that the underlying pathogenesis of this syndrome is more complex than the traditionally accepted vicious cycle. ${ }^{1}$ Although the circular events of repeated infections that incite inflammation that injure and disrupt the integrity of the airway thereby allowing for repeated infections are still relevant, a new, revised version of the traditional cycle, referred to as vortex, ${ }^{2}$ has been proposed. The vortex model more adequately describes the complexity of the underlying inflammation and remodeling steps that have much more complex interactions with each other. While immunodeficiency as a defined cause of bronchiectasis has fit nicely with the traditional vicious cycle model over the years, it too is now understood to be far more complex than once thought. Immunodeficiency is now known to involve complex autoinflammatory and autoim- munity mechanisms. Putting these two together, with an increased understanding of immune deficiencies related to bronchiectasis, our understanding of the pathogenesis of bronchiectasis may be enhanced as well.

Within the enormous landscape of immunodeficiency, both primary and secondary immune deficiencies are at play in the pathogenesis of bronchiectasis. International guidelines ${ }^{3-5}$ recommend investigation into the etiology bronchiectasis, to include evaluation for immunodeficiency as the potential cause of bronchiectasis.

\section{Primary Immunodeficiency}

Primary immune deficiencies (PIDs), also called inborn errors of immunity, result in inadequate or maladaptive immune response to the environment and to internal
Issue Theme Bronchiectasis: Advances in Diagnosis and Treatment; Guest Editor: James D. Chalmers, MBChB, PhD, FRCPE, FERS (c) 2021. Thieme. All rights reserved. Thieme Medical Publishers, Inc., 333 Seventh Avenue, 18th Floor, New York, NY 10001, USA
DOI https://doi.org/ 10.1055/s-0041-1730893. ISSN 1069-3424. 
stimuli. ${ }^{6}$ The result is an increased susceptibility to infection, autoimmunity, autoinflammatory diseases, allergy, and malignancy. There are over 400 distinct types of PIDs and this number, which has grown remarkably over the last two decades, is likely to continue to increase.

The International Union of Immunological Societies (IUIS) Expert Committee on human inborn errors of immunity organizes PIDs into 10 groups: combined immunodeficiencies; combined immunodeficiencies with syndromic features; predominantly antibody deficiencies; diseases of immune dysregulation; congenital defects of phagocytes; defects in intrinsic and innate immunity; autoinflammatory diseases; complement deficiencies; genes that cause bone marrow failure; and phenocopies of inborn errors of immunity. National and international registries have been established in the United States and Europe to improve knowledge of these disorders and aid in clinical research. In both the United States and European registries, common variable immunodeficiency (CVID) is the most common PID. ${ }^{7,8}$

\section{Common Variable Immunodeficiency}

Common variable immunodeficiency is a diagnosis of exclusion, to be assigned only after more well-defined syndromes with Mendelian inheritance have been considered and ruled out. $^{9}$ Since it was first named by the World Health Organization in $1971,^{10}$ the International Union of Immunological Societies Expert Primary Immunodeficiency Committee renamed CVID as "CVID disorders," 11 which retains the familiar acronym but additionally acknowledges the tremendous heterogeneity that is inherent in the diagnosis. There is more than one set of diagnostic criteria for the diagnosis CVID, ${ }^{12-14}$ but basic tenets of the diagnosis include a marked decrease in immunoglobulin $\mathrm{G}$ ( $\operatorname{IgG}$ ) along with a decrease in either IgA or IgM, the absence of an alternative cause for hypogammaglobulinemia, and a poor response to vaccination. It should be noted that diagnostic criteria are frequently evolving, and the diagnosis can be murky even for immunologists. Intravenous immunoglobulin (IV Ig), an effective therapy for CVID, is expensive and subject to supply versus demand shortage. This has led some to propose more stringent diagnostic criteria that include histological markers of CVID ${ }^{13}$ to best determine the most appropriate recipients of IV Ig. A detailed description of the diagnosis of CVID according to the International Consensus Document (ICON) is shown in - Table 1. CVID disorders can manifest from childhood to old age. Often there is confusion from other causes of hypogammaglobulinemia that may be transiently present at younger age. Furthermore, clinical manifestations and laboratory abnormalities do not always occur concomitantly. To accommodate for these complicating factors, it is recommended to refrain from the diagnosis of CVID until at least 4 years of age.

\section{Epidemiology of Common Variable Immunodeficiency}

Globally, the physician reported prevalence of CVID is 11,996 with the highest areas in the United States at 4,833 and western Europe at $3,439 .{ }^{15}$ Detection of PID as a whole has increased over recent years, by $32.7 \%$ from 2013 to 2018 in the United States and by $12 \%$ in the western Europe over the same time period. Men and women are equally affected, but there may be a racial difference. CVID appears to be less common in African Americans, although this observation is based largely on European American study populations. Although adult patients often provide history of childhood symptoms suggestive of an immune disorder, the diagnosis is most often made during adulthood, between the ages of 20 and 45 years. Some studies note that diagnosis is delayed up to 15 years. $^{16}$

\section{Clinical Spectrum of Common Variable Immunodeficiency}

The clinical spectrum of CVID consists of two main phenotypes: primarily recurrent infections and recurrent infections with autoimmune and/or inflammatory features. - Table 2 summarizes recurrent infections and autoimmune and inflammatory features of patients with CVID. The autoimmune or inflammatory manifestations of CVID may predate detection of CVID and can mimic other inflammatory or autoimmune diseases such as sarcoidosis or celiac disease. In a U.S. study of 455 CVID patients, granulomas were present in $8.1 \%$ of the patients and were identified 1 to 18 years before the diagnosis of CVID. ${ }^{17}$ Sinopulmonary infections are most often cited in large case studies of patients with CVID. ${ }^{16,18}$ A 12-month prospective study of 12 patients with primary hypogammaglobulinemia depicts the dominance of respiratory infections in these patients. The patients, all of who were receiving immune globulin replacement, underwent nasal swabs and induced sputum at the onset of respiratory tract infections and every 3 months thereafter. The 12 patients had 65 episodes of acute respiratory infections versus only 12 acute episodes noted in the 11 spouses who served as controls. The most common bacteria identified in patients were Moraxella catarrhalis (29\%) and Haemophilus influenzae (22\%). Rhinovirus was the most common respiratory virus identified. It was identified in the sputum in $54 \%$ of patient infection episodes. Viral PCR was additionally performed every 2 weeks after a viral infection episode and revealed the extended persistence of virus in these patients. Rhinoviral PCR was positive for 8 weeks in seven patients with CVID and for 5 months in a patient with X-linked agammaglobulinemia (XLA).

\section{Common Variable Immunodeficiency and Bronchiectasis}

Of all PIDs, pulmonary complications are most prevalent in CVID. An analysis of 1,937 PID patients registered in the U.S. Immunodeficiency Network (USIDNET) found that $61.7 \%$ of patients with CVID were reported as having pulmonary disease. ${ }^{19}$ The study further narrowed pulmonary disease by type and revealed that the highest prevalence of airway disease was in CVID patients. Nearly 58\% of CVID patients were reported to have airway disease (which included 
Table 1 Diagnosis of common variable immunodeficiency disorders ${ }^{14,32}$

\begin{tabular}{|c|c|c|c|}
\hline Criteria & & Value for diagnosis & Comment \\
\hline \multirow[t]{3}{*}{ Laboratory data } & $\lg G$ & $\begin{array}{l}\text { Lower than the age-adjusted reference range } \\
\text { Absolute lower limit }=4.5 \mathrm{~g} / \mathrm{L} \text {, but the diag- } \\
\text { nostic criteria can be fulfilled with higher levels }\end{array}$ & \multirow{2}{*}{$\begin{array}{l}\text { Must be repeated in at least } 2 \text { measure- } \\
\text { ments more than } 3 \text { weeks apart } \\
\text { Normal values are typically reported as } 2 \\
\text { SDs above or below the mean or the } \\
5 \text { th-95th percentile intervals }\end{array}$} \\
\hline & $\lg A$ or $\lg M$ & $\begin{array}{l}\text { Low }{ }^{\mathrm{b}} \\
\text { If IgM is high in the setting of low IgG and IgA, } \\
\text { consider hyper-lgM syndrome or defects of } \\
\text { class switch }\end{array}$ & \\
\hline & $\lg \mathrm{E}$ & & $\begin{array}{l}\text { Low IgE is not necessary to diagnose CVID, } \\
\text { but elevated IgE should prompt consider- } \\
\text { ation and workup of alternative diagnosis of } \\
\text { immune dysregulation }\end{array}$ \\
\hline Vaccine response & $\begin{array}{l}\text { Pre-vaccine measurement and } \\
\text { post-vaccine response ( } 4 \mathrm{wk} \\
\text { after vaccine if pre-vaccination } \\
\text { levels are low): } \\
\text { T-dependent (protein or } \\
\text { glycoprotein) antigens: } \\
\text { - Tetanus or } \\
\text { - Diphtheria toxoids or } \\
\text { - Haemophilus influenza } \\
\text { type B } \\
\text { and } \\
\text { Post-vaccinationc response to: } \\
\text { T-independent (polysac- } \\
\text { charide) antigens: } \\
\text { - Pneumococcal } \\
\text { - Conjugate polysaccharide } \\
\text { - Prevnar-13 (United States) } \\
\text { - Prevenar-13 (Europe) } \\
\text { - Pure polysaccharide } \\
\text { - Pneumovax (PPV23) }\end{array}$ & $\begin{array}{l}\text { Tetanus toxoids }<0.15 \mathrm{IU} / \mathrm{mL} \\
\text { Haemophilus influenzae type } \mathrm{B}<1 \mu \mathrm{g} / \mathrm{mL} \\
\text { Titers for assessing response to pneumococcal } \\
\text { conjugate vaccine have not been established } \\
\text { Pure pneumococcal polysaccharide: } \\
\text { Impaired memory: }>70 \% \text { protective titers } \\
\text { ( }>1.3 \mu \mathrm{g} / \mathrm{mL}) \text { for adults but lose this response } \\
\text { within } 6 \mathrm{mo} \\
\text { Mild: } \leq 1.3 \mu \mathrm{g} / \mathrm{mL} \text { in multiple serotypes or } \\
\text { failure to generate a twofold increase in } \geq 70 \% \\
\text { of the serotypes (patients aged } 6-65 \mathrm{y}) \\
\text { Moderate: }<70 \% \text { of the serotypes are } \geq 1.3 \mu \text { - } \\
\text { g/mL, but at least three serotypes are }>1.3 \mu \text { - } \\
\text { g/mL } \\
\text { Severe: no more than two serotypes show } \\
\text { protective serotypes }(>1.3 \mu \mathrm{g} / \mathrm{mL}) \text { and the } \\
\text { protective titers are low }(1.3-2.0 \mu \mathrm{g} / \mathrm{mL} \text { ) }\end{array}$ & $\begin{array}{l}\text { Vaccine response must be measured prior } \\
\text { to initiation of immunoglobulin replace- } \\
\text { ment therapy. Some experts may forego } \\
\text { vaccine testing in the setting of character- } \\
\text { istic phenotype with low lgG and IgA levels } \\
\text { to facilitate more rapid initiation of therapy } \\
\text { Vaccine responses may be impaired by } \\
\text { prolonged use of systemic corticosteroids }\end{array}$ \\
\hline $\begin{array}{l}\text { Exclusion of other } \\
\text { causes }\end{array}$ & & $\begin{array}{l}\text { Immune globulin loss: } \\
\text { - Nephrotic syndrome } \\
\text { - Protein-losing enteropathy } \\
\text { - Severe burns } \\
\text { - Lymphangiectasia } \\
\text { Medications: } \\
\text { - Antiepileptics (carbamazepine, phenytoin) } \\
\text { - Antimalarial agents } \\
\text { - Captopril } \\
\text { - Fenclofenac } \\
\text { - Glucocorticoids (systemic) } \\
\text { - Gold salts } \\
\text { - Penicillamine } \\
\text { - Rituximab } \\
\text { - Sulfasalazine } \\
\text { Malignancy: } \\
\text { - Chronic lymphocytic leukemia } \\
\text { - Lymphomas } \\
\text { - Good's syndrome (thymoma with immuno- } \\
\text { deficiency) } \\
\text { - Monoclonal gammopathy } \\
\text { Viral infections } \\
\text { Known immune defects }\end{array}$ & \\
\hline Gene sequencing & & & $\begin{array}{l}\text { Not required or recommended for diagno- } \\
\text { sis especially in the setting of infection as } \\
\text { the only clinical manifestation. } \\
\text { In the presence of autoimmunity, malig- } \\
\text { nancy, or other noninfectious complica- } \\
\text { tion, consider molecular genetic evaluation }\end{array}$ \\
\hline $\begin{array}{l}\text { Additional diagnos- } \\
\text { tic notes }\end{array}$ & & & $\begin{array}{l}\text { In the majority of patients, a characteristic } \\
\text { clinical manifestation (infection, autoim- } \\
\text { munity, lymphoproliferation) will be pres- } \\
\text { ent at the time of diagnosis, but CVID can } \\
\text { be diagnosed in asymptomatic individuals if } \\
\text { the laboratory criteria are met, vaccine } \\
\text { response is inadequate, and other causes } \\
\text { have been excluded } \\
\text { Consider CVID a temporary designation } \\
\text { until additional clinical and genetic infor- } \\
\text { mation emerges }\end{array}$ \\
\hline
\end{tabular}

Abbreviations: CVID, common variable immunodeficiency; Ig, immunoglobulin.

${ }^{\mathrm{a}}$ May forego repeat measurement in patients with $\mathrm{IgG}<100-300 \mathrm{mg} / \mathrm{dL}$ to facilitate more rapid initiation of therapy.

bThe scenario of normal IgA and IgM with low IgG should be called "unspecified IgG deficiency" or "unspecified hypogammaglobulinemia” but should not be called CVID.

'Preimmunization levels may be falsely elevated. High titers of naturally occurring cross-reactive antipolysaccharide and antibodies may be present. These antibodies correlate poorly with functional activity. 
Table 2 Clinical manifestations of common variable immunodeficiency disorders

\begin{tabular}{|c|c|c|c|c|}
\hline Location & Infection & Autoimmunity & Inflammation & Malignancy \\
\hline Lung & $\begin{array}{l}\text { Bacteria } \\
\text { Viral }\end{array}$ & & $\begin{array}{l}\text { Lymphocytic and/or granulomatous } \\
\text { infiltrates (granulomatous lympho- } \\
\text { cytic interstitial lung disease) }{ }^{\mathrm{a}}\end{array}$ & Lung cancer \\
\hline $\begin{array}{l}\text { Gastrointestinal } \\
\text { tract }\end{array}$ & & Antienterocyte antibodies & $\begin{array}{l}\text { Lymphocytic and/or granulomatous } \\
\text { infiltrates } \\
\text { Noninfectious enteropathy: } \\
\text { - Colitis } \\
\text { - Gastritis }\end{array}$ & $\begin{array}{l}\text { Colorectal cancer } \\
\text { Esophageal cancer }\end{array}$ \\
\hline Liver & & $\begin{array}{l}\text { Nodular regenerative hy- } \\
\text { perplasia } \\
\text { Primary biliary cirrhosis }\end{array}$ & $\begin{array}{l}\text { Lymphocytic and/or granulomatous } \\
\text { infiltrates }\end{array}$ & \\
\hline $\begin{array}{l}\text { Hematologic: } \\
\text { - Lymph nodes } \\
\text { - Bone marrow }\end{array}$ & & $\begin{array}{l}\text { Immune-mediated throm- } \\
\text { bocytopenia } \\
\text { Hemolytic anemia } \\
\text { Pernicious anemia } \\
\text { Autoimmune neutropenia }\end{array}$ & $\begin{array}{l}\text { Lymphocytic and/or granulomatous } \\
\text { infiltrates of the lymph nodes, bone } \\
\text { marrow, and spleen }\end{array}$ & $\begin{array}{l}\text { Lymphoma, most often } \\
\text { B cell origin (non-Hodg- } \\
\text { kin's lymphoma most } \\
\text { frequent) } \\
\text { Mucosa-associated lym- } \\
\text { phoid tissue lymphomas }\end{array}$ \\
\hline $\begin{array}{l}\text { Connective } \\
\text { tissue: } \\
\text { - Joints } \\
\text { - Skin }\end{array}$ & Septic arthritis & $\begin{array}{l}\text { Sjogren's disease } \\
\text { Sicca } \\
\text { Juvenile and rheumatoid } \\
\text { arthritis } \\
\text { Juvenile spondyloarthritis } \\
\text { Undifferentiated arthritis } \\
\text { Vitiligo } \\
\text { Alopecia }\end{array}$ & Granulomas & $\begin{array}{l}\text { Melanoma and other } \\
\text { skin cancer }\end{array}$ \\
\hline Brain & & & $\begin{array}{l}\text { Lymphocytic and/or granulomatous } \\
\text { infiltrates }\end{array}$ & \\
\hline Kidneys & & & $\begin{array}{l}\text { Lymphocytic and/or granulomatous } \\
\text { infiltrates }\end{array}$ & \\
\hline Thyroid & & Thyroiditis & & Thyroid cancer \\
\hline \multirow[t]{2}{*}{ Retinas } & & & Granulomas & \\
\hline & & & & $\begin{array}{l}\text { Other: breast uterine, } \\
\text { ovary, vaginal, and neu- } \\
\text { rogenic malignancies } \\
\text { have been reported }\end{array}$ \\
\hline
\end{tabular}

aLung and lymphoid tissue are the most frequent locations for granulomatous inflammation in common variable immunodeficiency.

bronchiectasis). Thus, bronchiectasis is common in CVID. Other studies have suggested that there are factors other than antibody level that allow for the development of bronchiectasis in CVID patients. In a separate analysis of the USIDNET registry, pulmonary complications were compared between CVID and XLA. ${ }^{20}$ Respiratory infections, pneumonia, and bronchiectasis were more common in CVID patients than in XLA patients despite a higher IgG levels. At the same time, CVID patients manifested lower levels of $\mathrm{CD}^{+}$and $\mathrm{CD} 8^{+} \mathrm{T}$ cells compared with XLA patients. This follows a previous observation correlating bronchiectasis with low $\mathrm{CD}^{+}{ }^{+} \mathrm{T}$ cells. ${ }^{21}$ A variety of interstitial lung diseases are also seen in CVID patients and similar to the prevalence of bronchiectasis, they are more common in CVID patients compared with XLA patients despite the profoundly lower antibody level in XLA. ${ }^{20}$

Shifting focus from bronchiectasis within PID communities to PID within bronchiectasis communities can be additionally informative. National and international bronchiectasis registries provide insight. The U.S. Bronchiectasis Research Registry was established in 2008 and currently includes 18 sites and approximately 3,800 registered bronchiectasis patients. As of 2017, when the registry included 2,710 patients, CVID accounted for $2.9 \%$ of the population. ${ }^{22}$ These patients were 64 (SD 12.5) years of age at diagnosis of bronchiectasis and 66.9 (SD 10.5) at the time of enrollment in the registry. Sixty-one percent experienced bronchiectasis exacerbations within the prior 2 years and $44.4 \%$ had been hospitalized during the same time. Lung function in this group as measured by percent forced expiratory volume in 1 second (FEV1\%) predicted was 75 (SD 20.9). Microbiologic culture analysis revealed that 25\% grew Pseudomonas aeruginosa and $43 \%$ grew nontuberculous mycobacteria. These data expose the late age in which some immunodeficient patients are diagnosed with bronchiectasis and reveal the severity of their disease as measured by pathogenic 
organisms and hospitalizations that correlate with more severe disease. ${ }^{23,24}$ Interestingly, in the United States, the prevalence of only $2.9 \%$ of the bronchiectasis population is lower than other areas. Other areas seem to capture a higher prevalence: $5.8 \%$ of 1,258 patients enrolled in various European centers were identified as having immunodeficiencyrelated cause of bronchiectasis. ${ }^{25}$ In China, the proportion of bronchiectasis attributed to immunodeficiency varies according to location. In the northeastern coastal region, $3.8 \%$ of bronchiectasis is attributed to immunodeficiency ${ }^{26}$ and in southern China the percentage is $8.8 .^{27}$ In Singapore, immunodeficiency was identified in $7.7 \%$ of a cohort of 181 bronchiectasis patients. ${ }^{28}$ Using the Australian Bronchiectasis Registry, Visser et al reported immunodeficiency in 3.7\% of a cohort of 589 with mostly moderate to severe bronchiectasis patients from six centers across the states of New South Wales and Queensland. ${ }^{29}$ Only India reports a smaller percentage of immunodeficiency compared with the United States at less than $1 \%$ of their population. ${ }^{30}$

It is not clear to what degree of stringency immunodeficiency has been diagnosed within the international bronchiectasis community. Most registries report "immunodeficiency" as the cause of bronchiectasis rather than referring to a more specific etiology. The seemingly small number and percentage of CVID patients within international registries suggest that not all CVID patients with bronchiectasis have found their way into bronchiectasis registries. One explanation for this may be that many CVID cases are not recognized.

\section{Specific Antibody Deficiency}

Specific antibody deficiency (SAD) refers to a reduced ability to produce antibodies to polysaccharide (pneumococcal) in the setting of normal immunoglobulins. ${ }^{31}$ SAD can occur in combination with a defined primary or secondary immunodeficiency or it can be the only immunologic abnormality present in a patient. SAD is also referred to as "impaired polysaccharide responsiveness," "selective antibody deficiency with normal immunoglobulins," and "antibody deficiency with near-normal immunoglobulins." It is unknown if a genetic defect or inheritance pattern is involved in this syndrome. $^{31}$ Clinically, patients with SAD manifest with recurrent sinopulmonary infections. It appears that clinical symptoms may be more severe as the severity of antibody nonresponsiveness increases. Antibody response to polysaccharide has been stratified in a working group report into memory, mild, moderate, and severe ${ }^{32}$ (- Table 1). In an analysis of 595 patients with chronic rhinosinusitis, $40.2 \%$ were identified as having SAD. ${ }^{33}$ Within the population, mild, moderate, and severe SADs were present in 39.8, 50.2 , and $10 \%$, respectively. The clinical characteristics of these patients were then compared according to severity of their response to polysaccharide responses. The investigators found that patients with moderate and severe SAD were more likely to have a history of pneumonia and they required more courses of antibiotics in the 2-year period after vaccination than patients with mild SAD. Of note, the study also analyzed a healthy control population and found SAD to be present in $20.4 \%$ of the healthy cohort using the same working group report stratification. In the healthy population with SAD, mild, moderate, and severe SADs were present in 45,40 , and $15 \%$, respectively.

Regarding SAD in bronchiectasis, Vendrell and colleagues analyzed antibody responses to both the 23-valent pneumococcal vaccine and the Hib-conjugate vaccine in 107 patients with idiopathic bronchiectasis who had normal IgG levels. ${ }^{34}$ They found that $11 \%$ of the population failed to respond to either the pneumococcal vaccine or the $H$. influenzae type B vaccine. These patients were deemed to have antibody production deficiency. In addition, 20 patients (19\%) did not respond to the pneumococcal vaccine only. Sputum microbiology, extent of bronchiectasis, pulmonary function, and pneumonia history did not differ between bronchiectasis patients with and without an antibody production deficiency. These data suggest that SAD prevalence in bronchiectasis may be similar to the healthy population and that the presence of SAD, at least in bronchiectasis, does not seem to correlate with clinical features as it does in chronic rhinosinusitis patients. In contrast, van Kessel and colleagues $^{35}$ analyzed antipneumococcal antibody responses in 26 idiopathic bronchiectasis patients, all of who had normal total immunoglobulin levels. Four patients (15.3\%) demonstrated abnormal responses to the 23-valent pneumococcal vaccine ("total nonresponders"). The investigators further analyzed the same group using more stringent criteria. They analyzed isotype-specific antibodies (IgA, IgG1, and $\operatorname{IgG} 2$ ), serotypes $4,6 \mathrm{~B}, 9 \mathrm{~V}, 14,19 \mathrm{~F}$, and $23 \mathrm{~F}$. Using these more strenuous criteria, they found that $50 \%$ of their idiopathic bronchiectasis cohort demonstrated inadequate response to the vaccination. This group of patients was deemed "isotype nonresponders." The authors showed a trend toward more infections per year in the overall nonresponders (both isotype and total) compared with the normal responders to pneumococcal vaccination. These data suggest that interpretation of vaccination responses within the idiopathic bronchiectasis cohort may require a more analytical protocol than for the healthy population.

\section{Primary Immunodeficiencies Involving High Serum Immunoglobulin E}

In addition to its role in providing defense during parasite infection, IgE is also well known for its mechanistic role in asthma, allergic bronchopulmonary aspergillosis, and eosinophilic granulomatosis with polyangiitis (Churg-Strauss syndrome). Three distinct hyper-IgE syndromes (HIESs) are more recently described. They are STAT3 (signal transducer and activator 3), DOCK8 (dedicator of cytokinesis 8), and PGM3 (phosphoglucomutase 3). ${ }^{36}$ These three entities all share skin manifestations, sinopulmonary infections (including bronchiectasis), and elevated IgE, but each has specific nuances. Because these conditions require gene sequencing for diagnosis, specific attention is given to the clinical features to aid the clinician in recognition and referral to a specialty center. 


\section{Autosomal Dominant Hyper-IgE Syndrome}

Autosomal dominant hyper-IgE syndrome (AD-HIES) is a syndrome of skin abscesses and recurrent pyogenic pneumonias caused by dominant (or sporadic then passed down in an autosomal dominant pattern) mutations in STAT3. STAT3 is required for naive $\mathrm{T}$ lymphocytes to differentiate in Th17 lymphocytes. Th17 cells secrete cytokines (IL-17 and IL-22) that upregulate antimicrobial peptides at the mucosal level. A typical AD-HIES patient manifests head and upper body rash during infancy. The rash is initially diagnosed as neonatal acne or erythema toxicum neonatorum but eventually progressed to eczematous dermatitis that becomes chronically infected with Staphylococcus aureus. The moniker "Job's syndrome" was given to AD-HIES because the recurrent skin abscesses resembled boils described in the Bible that affected the prophet Job. ${ }^{37}$ Pneumonias from S. aureus and $H$. influenza occur during in the first several years of life, but diagnosis can delayed because of a diminished inflammatory response that accompanies this syndrome. Pneumatoceles, empyema, and bronchiectasis eventually develop in the majority of AD-HIES patients, suggesting that impaired epithelial repair is part of the pathogenesis. - Fig. 1 depicts an AD-HIES patient with a large pneumatocele. With recurrent pneumonias and the attendant changes to the lung architecture (bronchiectasis and pneumatoceles), the pathogenic organisms evolve to include Aspergillus fumigatus, P. aeruginosa, and nontuberculous mycobacteria. Patients with AD-HIES manifest a typical facial appearance of a prominent forehead and facial asymmetry, deep-set eyes, broad nasal bridge, a high arched palate, and rough skin. Characteristically, the majority of patients retain primary teeth which can lead to dental crowding without surgical intervention. Significant scoliosis, minimal trauma skeletal fractures (e.g., rib fractures from coughing), and flexible joints are also present in the majority of patients. Management of AD-HIES involves systemic prophylactic antimicrobial therapy, antiseptic baths (bleach baths) for skin lesions, and airway clearance (nebulized hypertonic saline) for bronchiectasis. A special consideration is the frequent hemoptysis seen in these patients due to the architectural distortion of pulmo-

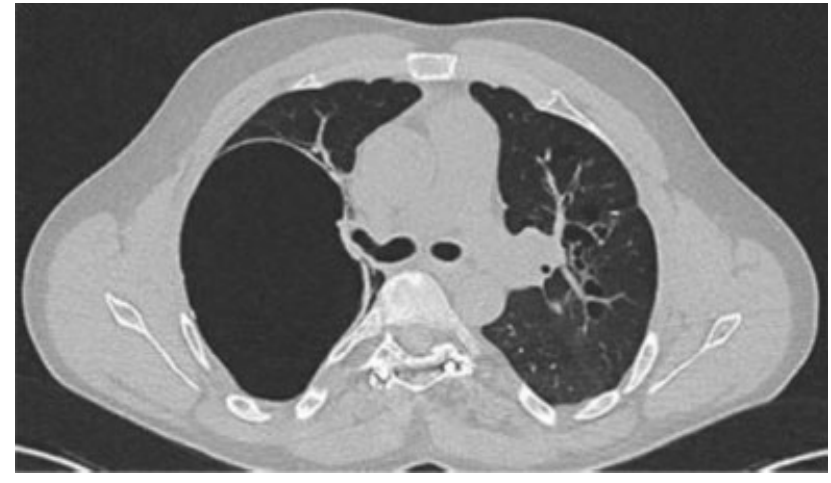

Fig. 1 Representative axial image from a computed tomography of the chest of a 28-year-old man with STAT3 mutated autosomal dominant hyper-IgE syndrome. (Photo courtesy of Kenneth N. Olivier, MD, MPH, National Heart Lung Blood Institute, National Institutes of Health, Bethesda, MD.)

nary parenchyma. ${ }^{38}$ Vigilance for this complication as well as a plan for its occurrence is indicated. In some instances, surgical resection for hemoptysis or large infected pneumatoceles is necessary, but this is uniquely challenging due to the high complication rate caused by impaired healing. Bronchopleural fistula is the most common surgical complication in these patients and may require further surgery or valve insertion. ${ }^{39}$

\section{DOCK8 Immunodeficiency Syndrome}

DOCK8 (dedicator of cytokinesis 8) encodes a protein that is important in both innate and adaptive immunity. It regulates actin cytoskeleton-dependent immune responses and is involved in migration of immune cells. ${ }^{40}$ DOCK8 immunodeficiency syndrome (DIDS) has an autosomal recessive inheritance pattern and is the result of homozygous or compound heterozygous deletions in DOCK8. Similar to AD-HIES, the condition presents during early childhood with a rash and frequent sinopulmonary infections. Bronchiectasis presumably results from recurrent bacterial and viral pneumonias. -Fig. 2 depicts bronchiectasis in a patient with DIDS. Atopy, severe food allergies leading to

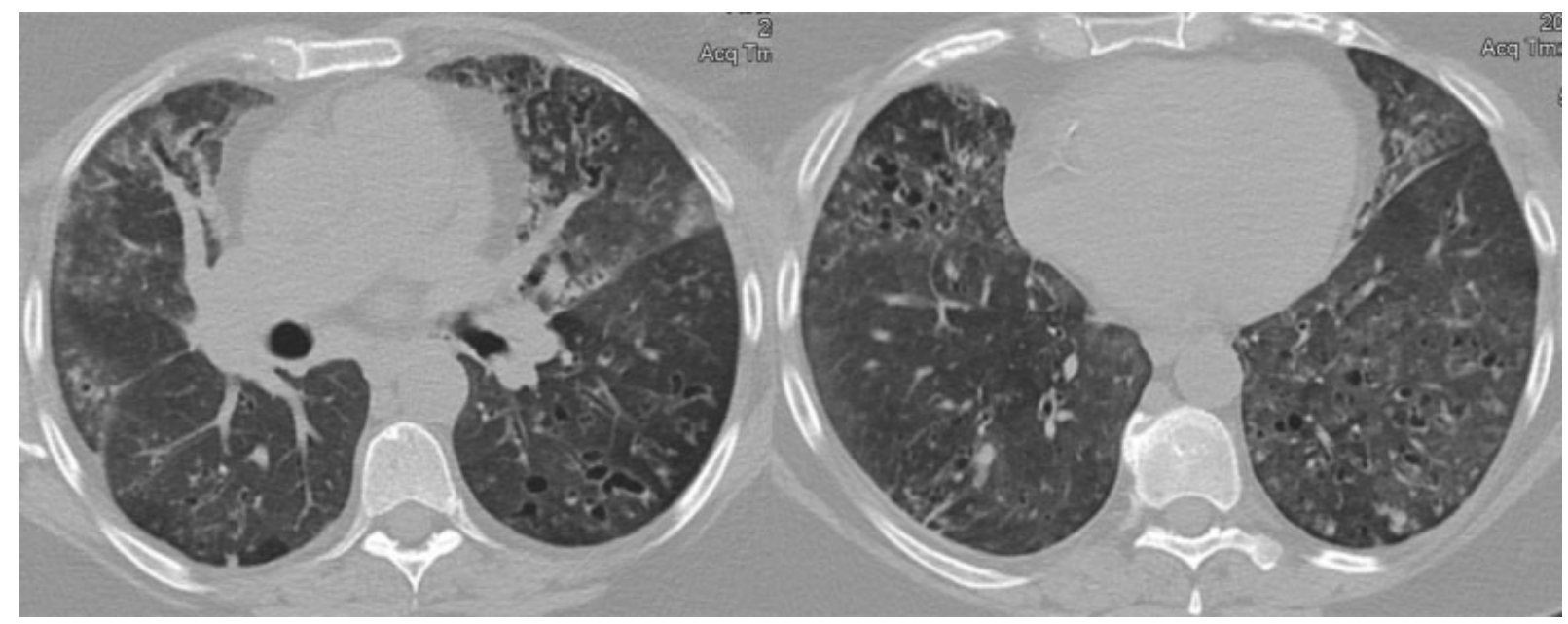

Fig. 2 Representative axial images from a computed tomography of the chest of a 44-year-old woman with DOCK8 deficiency. 
anaphylaxis, and asthma are more common in these patients than in AD-HIES patients. ${ }^{41}$ DOCK8 patients usually have elevation of IgE, a typically normal IgG and low IgM. Over time, DOCK8-deficient patients develop lymphopenia. A notable feature of DOCK8 deficiency that separates it from AD-HIES is the particular susceptibility to viral skin infections. DOCK8 deficiency makes lymphocytes unable to maintain cell shape during migration from skin lesions to lymph nodes, an event called cytothripsis. ${ }^{42}$ This also results in impaired tumor surveillance, leading to viral-mediated malignancy seen in this population. Vasculitis of the middle and large size blood vessels is infrequently seen in DIDS patients at much younger age than in the general population. ${ }^{41}$ The mainstay of therapy for DOCK8-deficient patients are prophylactic antimicrobials and immune supplementation. Hematopoietic stem cell transplantation reverses the key underlying immune defect and improves clinical features. ${ }^{43}$ Early referral for transplantation is important to avoid endorgan damage. A pilot study of reduced-intensity hematopoietic cell transplantation (HCT) for DOCK8 deficiency patients is currently underway with an estimated completion date of December 2023 (NCT01176006).

\section{PGM3 Deficiency}

PGM3 (phosphoglucomutase 3) is an enzyme required for glycosylation of proteins, a process required for adequate function of the majority of proteins in the body. PGM3 deficiency can result from hypomorphic (partial loss of function) homozygous and compound heterozygous mutations. ${ }^{44,45}$ The phenotype of PGM3 deficiency is broad ranging and can result in early-onset bone marrow failure, skeletal abnormalities, and cognitive delay ${ }^{46}$ to a more indolent hyper-IgE phenotype of allergies, atopic dermatitis, and recurrent sinopulmonary infections leading to bronchiectasis. ${ }^{47}$ Patients with PGM3 deficiency have an elevated IgE, neutropenia, and $\mathrm{CD}^{+}$lymphopenia. ${ }^{46}$

Supportive care with antimicrobial prophylaxis is indicated. Stem cell transplantation reverses the infection susceptibility but does not impact the neurocognitive dysfunction or skeletal abnormalities.

\section{Activated PI3 Kinase Delta Syndrome}

Phosphoinositide 3-kinase delta (PI3K $\boldsymbol{\delta}$ ) is a lipid kinase that engages with $B$ cells, $T$ cells, and cytokine and costimulatory receptors. PI3K $\delta$ contains a regulatory subunit (p85 $\alpha$ ) and a catalytic subunit ( $\mathrm{p} 110 \delta$ ). Mutations in the genes that encode these subunits can result in increased PI3K $\delta$ activity. ${ }^{48,49}$ Increased PI3K $\boldsymbol{\delta}$ activity causes both immunodeficiency and immune dysregulation. ${ }^{50}$ Clinically, the result includes recurrent respiratory infections, recurrent herpes family virus infections, benign and malignant lymphoproliferation, immune cytopenias, solid-organ autoimmunity, and, in some cases, developmental delays. ${ }^{50}$ The "gain-of-function" gene mutations that occur in the PI3K $\delta$ subunits are autosomal dominant. They were discovered by using whole-exome sequencing to analyze PID patients of unknown etiology from unrelated families. ${ }^{48,49}$ Activated PI3K $\delta$ syndrome (APDS) is also referred to as PASLI (p110 $\delta$-activating mutation causing senescent $\mathrm{T}$ cells, lymphadenopathy, and immunodeficiency). Two characteristic phenotypes of APDS (APDS 1 and APDS 2) have been observed. ${ }^{51-53}$ Both phenotypes universally experience repeated respiratory infections, but the APDS 1 phenotype seems to manifest more bronchiectasis than the APDS 2 phenotype (60 vs. $18 \%$, respectively) despite having normal IgG levels. The fact that IgG levels are normal in the context of this bona fide PID is an important reminder to the nonimmunologist clinician to look beyond Ig levels when evaluating a seemingly idiopathic bronchiectasis case. Importantly, a majority of APDS patients have elevated IgM and some have been reported as being misdiagnosed as hyper-IgM syndrome. ${ }^{48}$

Like other PIDs, APDS is treated with airway clearance for bronchiectasis, prophylactic antibiotics, and immunoglobulin replacement therapy. Hematopoietic stem cell transplantation has been described as a therapy in young patients, but longer follow-up is needed to confirm initial successful results. $^{52,53}$ Rapamycin, an mTOR inhibitor, has been reported to reduce lymphadenopathy and splenomegaly in APDS patients. However, multiple other regulating pathways that are involved in the relationship between mTOR and PI3K $\delta$ make rapamycin a less-than-ideal therapy. The identification of the gene mutations that cause APDS and their role in increasing PI3K $\delta$ activity has allowed for the development of more targeted therapies. PI3K $\delta$ inhibitors are currently being studied in APDS patients. A phase II clinical trial of leniolisib (CDZ173), an oral PI3K $\delta$ inhibitor, is currently enrolling and has an expected completion date of June 2021 (NCT02435173). A separate phase II trial of nemiralisib, a PI3K $\boldsymbol{\delta}$ inhibitor via dry powder inhaler, has recently completed (NCT02593539).

\section{X-Linked Agammaglobulinemia}

X-linked agammaglobulinemia was the first described immunoglobulin deficiency. In 1952, Dr. Ogden Bruton described a case of complete absence of IgG in an otherwise normal 8-year-old boy. ${ }^{54} \mathrm{XLA}$ is now known to result from a defective gene located on the $\mathrm{X}$ chromosome that encodes a protein-tyrosine kinase that is critical for the development of B cells. ${ }^{55,56}$ The gene has now been renamed the Bruton tyrosine kinase or BTK gene. XLA patients have severe reduction in all immunoglobulins and profoundly decreased B cells. ${ }^{55,56}$ XLA is relatively uncommon. In a 2006 report, the estimated U.S. prevalence was $1 / 190,000$ live male births from 1988 to $1997 .{ }^{57}$ More recently, the United Kingdom reported 0.3 per 100,000 from the UK Primary Immunodeficiency registry in which XLA made up $4.4 \%$ of the registered patients as of $2017 .^{58}$

A minority of patients are diagnosed at birth based on family history. The majority are diagnosed only after recurrent infections manifest. ${ }^{58}$ Clinical symptoms of XLA manifest between 3 and 18 months of age after the protective effects of maternal immunoglobulins diminish. ${ }^{57}$ The most common clinical symptoms in these patients result from 
bacterial infections. ${ }^{59}$ In particular, Streptococcus pneumoniae, $H$. influenzae type B, Streptococcus pyogenes, and Pseudomonas species are reported. ${ }^{57}$ The respiratory and gastrointestinal tracts are frequent sites of infection. Unfortunately, respiratory infections continue to be recurrent despite adequate immunoglobulin therapy. ${ }^{57,60,61}$ In a study of 73 patients aged 2 to 33 years, chronic lung disease was present in $33 \%$ of the cohort and was more likely to be present with delayed diagnosis. ${ }^{60}$ The authors calculated that XLA patients have a 25-year post diagnosis risk of $92 \%$ to develop chronic lung disease. Regrettably, once bronchiectasis has developed in XLA patients, it progresses despite IgG replacement therapy. ${ }^{61}$ The progression of bronchiectasis may be due to the fact that the XLA patients remain IgM and IgA deficient despite IgG replacement. In addition, inflammatory mechanisms in the airway that have yet to be identified may be contributing as well. The lack of $B$ lymphocytes and their regulation of inflammatory regulation has been proposed as a mechanism of inflammatory and autoimmunity complications in these patients. ${ }^{62}$

\section{Secondary Immunodeficiencies}

\section{Chronic Graft versus Host Disease}

Chronic graft versus host disease (cGVHD) is a significant complication that typically presents at least 100 days after, but within 3 years of allogeneic HCT. ${ }^{63}$ The pathogenesis of cGVHD is not completely understood, but it resembles more of an autoimmune phenomenon rather than an immunodeficiency. It is included in this section, as HCT patients are generally considered in the context of immunesuppressed state.

In the absence of biopsy-proven bronchiolitis obliterans (the only diagnostic manifestation of cGVHD), the diagnosis can be made by a constellation of clinical findings that must include airflow obstruction (FEV1/forced vital capacity $<0.7$ and FEV1 $<75 \%$ of predicted) and high-resolution computed tomography evidence of air trapping, small airway thickening, or bronchiectasis. ${ }^{63}$ These criteria must exist in the absence of respiratory infection. Bronchiectasis that occurs in the context of cGVHD can be severe and rapidly progressive, ${ }^{64}$ and has been described as resulting in severe cystic bronchiectasis over only 2 years. ${ }^{65}$ Airway infection with $S$. aureus and $P$. aeruginosa is described. Although the mortality associated specifically with bronchiectasis in these patients is unknown, in HCT recipients who survive longer than 2 years, those who have pulmonary dysfunction been identified as having a 15 -fold increased risk of late deaths ${ }^{66}$ compared with the general population. This underscores the need for close monitoring and aggressive interventions in patients who manifest decline in lung function. Patients with early pulmonary cGVHD may be asymptomatic or manifest nonspecific symptoms. ${ }^{67}$ As such, screening with routine pulmonary function, surveillance for infection, and elimination of exacerbating factors such as gastroesophageal reflux is recommended. ${ }^{68}$ Some studies have shown benefit from inhaled corticosteroids in cGVHD patients with obstructive airway disease. ${ }^{69,70}$ However, this benefit must be balanced by recent data pointing toward an increased risk of pneumonia $^{71}$ and nontuberculous mycobacterial infection ${ }^{72}$ in patients with chronic obstruction pulmonary disease who receive inhaled corticosteroids. For patients with life-threatening pulmonary cGVHD, lung transplantation is performed with similar survival at 1,3 , and 5 years as matched controls with other end-stage lung diseases. ${ }^{73}$

\section{Malignancy}

Bronchiectasis that develops in patients with hematologic malignancy is presumably related to the immunodeficiency caused by the malignancy itself or chemotherapy administered during the disease. Hematologic malignancies, such as multiple myeloma and chronic lymphocytic leukemia, result in reduced levels of immunoglobulin levels ${ }^{74,75}$ and attendant risk of infection. In a description of patients with combined bronchiectasis and hematologic malignancy, 27\% of who had not received HCT, bronchiectasis demonstrated progression over time in terms of airway dilation and bronchial wall thickening. P. aeruginosa was grown from $30 \%$ of sputum cultures. Immunoglobulin deficiency was not ubiquitous, present in 59\%, and all but one patient had received chemotherapy. The constellation of findings in this report makes it difficult to implicate the exact cause of bronchiectasis. Taking the influence of chemotherapy out of the equation, a radiographic analysis of 49 patients with adult T-cell leukemia (ATL) at the time of diagnosis and before any therapeutic intervention revealed CT findings bronchiectasis in $22 \%$ of the population. ${ }^{76}$ Further analysis comparing aggressive and indolent ATL showed no significant difference in bronchiectasis prevalence between the two types of disease. In an earlier retrospective review of CT scans performed at the time of diagnosis of ATL, bronchiectasis was identified in $21.7 \%$ of the 60 patients. ${ }^{77}$ Surgical biopsy from one patient's area of bronchiectasis revealed atypical lymphocytes infiltrating the wall of respiratory bronchioles and extending into the peribronchiolar interstitium. This provocative finding could suggest that bronchiectasis results from the influence of malignant cells rather than immunosuppression that accompanies malignancy.

One malignancy that may be a lesser known association with bronchiectasis is thymoma in the context of hypogammaglobulinemia. Thymomas typically present in adults in the fifth and sixth decades of life and commonly incite paraneoplastic autoimmune complications that affect bone marrow precursors and the nervous system. Good's syndrome is thymoma accompanied by destruction of bone marrow precursors by CD8 $\mathrm{T}$ lymphocytes that result in pure B cell aplasia (hypogammaglobulinemia) and thymoma. Seventy-eight patients with Good's syndrome who were registered in the UK-Primary Immune Deficiency Registry reviewed for clinical and laboratory features. ${ }^{78}$ Forty-five percent of the cohort overall had bronchiectasis. The prevalence of bronchiectasis was further analyzed by histologic type; type $A B$ thymomas (those with higher content of immature $T$ cells) had the highest prevalence of bronchiectasis at $59 \%$ (vs. 25,0 , and $22 \%$ in types $\mathrm{A}, \mathrm{B}$, and C, respectively). 
Thus far, the discussion has focused primarily on bronchiectasis identified in the patient with known malignancy. Importantly, bronchiectasis has been noted to be the clinical presentation of malignancy such as relapsed B-cell lymphoma. ${ }^{79}$ This highlights the importance of following guidelines ${ }^{3}$ which recommend performing a thorough workup for etiology in a patient who presents with bronchiectasis to ensure the successful identification of a previously unidentified malignancy.

\section{Human Immunodeficiency Virus}

In the acute infection stage, human immunodeficiency virus (HIV) binds to macrophages ${ }^{80}$ and dendritic cells, ${ }^{81}$ typically in epithelium and then fuses with $\mathrm{CD} 4^{+} \mathrm{T}$ cells. The infected $\mathrm{T}$ cells spread to lymph nodes and into plasma at which point there is widespread dissemination to peripheral organs. ${ }^{82}$ At this stage of highest host susceptibility, viral replication is rapid and $\mathrm{CD}^{+}{ }^{+} \mathrm{T}$ cells decline precipitously. The low $\mathrm{CD} 4^{+}$ cell count that is characteristic of the disease is an undeniable risk factor in the development of respiratory infections. $^{83}$ Recurrent pneumonias and pulmonary Mycobacterium tuberculosis are AIDS-defining conditions, but at the same time they are dominant etiologies of bronchiectasis independent of HIV. ${ }^{26,27,84,85}$ This suggests that bronchiectasis in HIV patient may be the sequelae of pneumonias contracted early in the course of their HIV infection rather than an on-going process acquired later in the course of HIV status. Even in studies of children with bronchiectasis and HIV, bronchiectasis was much more likely to develop in children who had a history of recurrent pneumonia. ${ }^{86}$ Moving beyond the CD4 level and its accompanying burden of respiratory infection risk, HIV also results in neutropenia and aberrant neutrophil functions, including neutrophil chemotaxis, phagocytosis, bactericidal activity, and oxidative burst activity. ${ }^{87}$ In a study of HIV patients on antiretroviral therapy with viral load less than 20 RNA copies and CD4 count greater than 350 cells $/ \mathrm{mm}^{3}$, neutrophils were found to exhibit hyperactivation and deregulated apoptosis. This mirrors recent discovery of the underpinnings of bronchiectasis pathophysiology in non-HIV individuals. Bedi and colleagues have shown that neutrophil dysfunction such as prolonged survival and impaired bacterial phagocytosis and killing is important driver of bronchiectasis pathophysiology in idiopathic bronchiectasis. ${ }^{88,89}$

Unfortunately, description of concomitant bronchiectasis and HIV is relatively sparse. Much of the literature is based on retrospective case series and is often hindered by variable patient follow-up and adherence to therapy. Furthermore, description of workup for an alternative etiology other than HIV in the patient cohort is typically not available. For example, a case series from two urban U.S. centers of individuals who ranged in age from 12 to 77 included three congenitally acquired cases of HIV on antiretroviral therapy. No workup of alternative causes for bronchiectasis was available despite some descriptions included features that were suggestive of primary ciliary dyskinesia. This highlights the need for registries and prospective studies that follow up patients over time. These studies may not only clarify the connection of bronchiectasis and HIV but also reveal pathophysiologic mechanisms that drive bronchiectasis even in the non-HIV patient.

\section{Immunoglobulin Replacement Therapy}

Immunoglobulin replacement therapy is used in a vast number of clinical entities from to infection to autoimmunity to neurologic disorders and beyond. ${ }^{90}$ For certain diseases, immunoglobulin replacement is an absolute essential aspect of therapy. For many other diseases, it provides supplemental clinical benefit by way of anti-inflammatory and immunomodulating effects. Regarding bronchiectasis, immunoglobulin replacement should be used in the setting of absent or deficient antibody production (-Table 1). Immunoglobulin replacement consists of liquid concentrates of IgG recovered from plasmapheresis of human donors. Multiple steps including donor screening, pooled plasma nucleotide testing, nanofiltration, and treatment with inactivating detergents are utilized to reduce the risk of viral transmission to near zero.

The primary goal of IgG therapy is to improve the patient's frequency of infections. The specific trough IgG level required to achieve this outcome will vary from patient to patient. ${ }^{91}$ Therefore, the patient's frequency of infection should be the primary parameter for increasing the maintenance dose. Bronchiectasis patients seem to require higher doses than patients without bronchiectasis. In a 22-year prospective study of 90 clinically phenotyped patients with CVID, the relationship between IgG dose, trough IgG level, and infection rates was analyzed. ${ }^{91}$ Bronchiectasis patients received a mean dose of $0.70( \pm 0.29) \mathrm{g} / \mathrm{kg} / \mathrm{mo}$ compared with $0.53( \pm 0.20) \mathrm{g} / \mathrm{kg} / \mathrm{mo}$ for patients without bronchiectasis to achieve equivalent IgG trough levels and similar infection score per patient-period. The regression coefficient for trough IgG levels against replacement dosing for bronchiectasis patients was also analyzed. Every $0.1 \mathrm{~g} / \mathrm{kg} /$ mo increase in replacement dose yielded an increase in trough by $0.41 \mathrm{~g} / \mathrm{L}$. This regression coefficient was much lower than for patients without bronchiectasis. In practice, an initial starting dose of $0.6 \mathrm{mg} / \mathrm{kg} / \mathrm{mo}$ can be used and then adjusted according to clinical outcomes. Many intravenous and subcutaneous formulations of IgG are available. These products are proprietary and not interchangeable. Replacement therapy can be administered in a hospital, infusion center, outpatient office, or home setting. The frequency of administration depends on the route of delivery and ranges from days (subcutaneous form) to every 3 to 4 weeks (intravenous form). The exact product should be selected based on the patient's clinical variables and preferences. Additional considerations when using IgG products include an awareness of maltose-containing products in the setting of diabetics; the presence of isohemagglutinins in IV IgG which may contribute to hemolysis ${ }^{90}$; and varying levels of IgA, sodium, and osmolality unique to each product. Some common side effects of IgG therapy include headache, myalgia, arthralgia, chills, malaise, fatigue, fever, rash, nausea, hypoor hypertension, tachycardia, and fluid overload. ${ }^{90}$ Side effects may be infusion rate related and more common with higher doses. 


\section{Conclusion}

Immunodeficiency is an important cause of bronchiectasis and is probably more prevalent than currently recognized. All patients with idiopathic bronchiectasis should undergo thorough evaluation for possible immunodeficiency. The identification of an immunodeficiency in this group impacts therapeutic management and provides an opportunity to improve clinical outcomes. In recent years, several distinct PIDs with characteristic bronchiectasis have been identified. Careful analysis and phenotyping of these groups has expanded understanding of immunodeficiency, especially about the relationship between immunodeficiency, autoimmunity, and autoinflammatory disease. As both PID and bronchiectasis registries have grown in number and size, so can the opportunity to learn more about underlying pathophysiology that links these two syndromes together.

\section{Conflict of Interest}

None declared.

\section{References}

1 Cole PJ. Inflammation: a two-edged sword-the model of bronchiectasis. Eur J Respir Dis Suppl 1986;147:6-15

2 Flume PA, Chalmers JD, Olivier KN. Advances in bronchiectasis: endotyping, genetics, microbiome, and disease heterogeneity. Lancet 2018;392(10150):880-890

3 Polverino E, Goeminne PC, McDonnell MJ, et al. European Respiratory Society guidelines for the management of adult bronchiectasis. Eur Respir J 2017;50(03):50

4 Chang AB, Bell SC, Torzillo PJ, et al; Extended Voting Group. Chronic suppurative lung disease and bronchiectasis in children and adults in Australia and New Zealand Thoracic Society of Australia and New Zealand guidelines. Med J Aust 2015;202(03):130

5 Pasteur MC, Bilton D, Hill ATBritish Thoracic Society Bronchiectasis Non-CF Guideline Group. British Thoracic Society guideline for non-CF bronchiectasis. Thorax 2010;65(Suppl 1):i1-i58

6 Tangye SG, Al-Herz W, Bousfiha A, et al. Human inborn errors of immunity: 2019 update on the classification from the International Union of Immunological Societies Expert Committee. J Clin Immunol 2020;40(01):24-64

7 Sullivan KE, Puck JM, Notarangelo LD, et al. USIDNET: a strategy to build a community of clinical immunologists. J Clin Immunol 2014;34(04):428-435

8 Seidel MG, Kindle G, Gathmann B, et al; ESID Registry Working Party and collaborators. The European Society for Immunodeficiencies (ESID) Registry Working Definitions for the Clinical Diagnosis of Inborn Errors of Immunity. J Allergy Clin Immunol Pract 2019;7(06):1763-1770

9 Cooper MD, Faulk WP, Fudenberg HH, et al. Classification of primary immunodeficiencies. N Engl J Med 1973;288(18): 966-967

10 Fudenberg H, Good RA, Goodman HC, et al. Primary immunodeficiencies. Report of a World Health Organization Committee. Pediatrics 1971;47(05):927-946

11 Notarangelo LD, Fischer A, Geha RS, et al; International Union of Immunological Societies Expert Committee on Primary Immunodeficiencies. Primary immunodeficiencies: 2009 update. J Allergy Clin Immunol 2009;124(06):1161-1178

12 Conley ME, Notarangelo LD, Etzioni ARepresenting PAGID (PanAmerican Group for Immunodeficiency) and ESID (European Society for Immunodeficiencies) Diagnostic criteria for primary immunodeficiencies. Clin Immunol 1999;93(03):190-197
13 Ameratunga R, Woon ST, Gillis D, Koopmans W, Steele R. New diagnostic criteria for common variable immune deficiency (CVID), which may assist with decisions to treat with intravenous or subcutaneous immunoglobulin. Clin Exp Immunol 2013;174 (02):203-211

14 Bonilla FA, Barlan I, Chapel H, et al. International Consensus Document (ICON): common variable immunodeficiency disorders. J Allergy Clin Immunol Pract 2016;4(01):38-59

15 Modell V, Orange JS, Quinn J, Modell F. Global report on primary immunodeficiencies: 2018 update from the Jeffrey Modell Centers Network on disease classification, regional trends, treatment modalities, and physician reported outcomes. Immunol Res 2018; 66(03):367-380

16 Oksenhendler E, Gérard L, Fieschi C, et al; DEFI Study Group. Infections in 252 patients with common variable immunodeficiency. Clin Infect Dis 2008;46(10):1547-1554

17 Ardeniz O, Cunningham-Rundles C. Granulomatous disease in common variable immunodeficiency. Clin Immunol 2009;133 (02):198-207

18 Kainulainen L, Nikoskelainen J, Ruuskanen O. Diagnostic findings in 95 Finnish patients with common variable immunodeficiency.J Clin Immunol 2001;21(02):145-149

19 Patrawala M, Cui Y, Peng L, et al. Pulmonary disease burden in primary immune deficiency disorders: data from USIDNET Registry. J Clin Immunol 2020;40(02):340-349

20 Weinberger T, Fuleihan R, Cunningham-Rundles C, Maglione PJ. Factors beyond lack of antibody govern pulmonary complications in primary antibody deficiency. J Clin Immunol 2019;39(04): 440-447

21 Maglione PJ, Overbey JR, Radigan L, Bagiella E, CunninghamRundles C. Pulmonary radiologic findings in common variable immunodeficiency: clinical and immunological correlations. Ann Allergy Asthma Immunol 2014;113(04):452-459

22 Eden E, Choate R, Barker A, et al. The clinical features of bronchiectasis associated with alpha-1 antitrypsin deficiency, common variable immunodeficiency and primary ciliary dyskinesiaresults from the U.S. Bronchiectasis Research Registry. Chronic Obstr Pulm Dis (Miami) 2019;6(02):145-153

23 Chalmers JD, Goeminne P, Aliberti S, et al. The bronchiectasis severity index. An international derivation and validation study. Am J Respir Crit Care Med 2014;189(05):576-585

24 Martínez-García MA, de Gracia J, Vendrell Relat M, et al. Multidimensional approach to non-cystic fibrosis bronchiectasis: the FACED score. Eur Respir J 2014;43(05):1357-1367

25 Lonni S, Chalmers JD, Goeminne PC, et al. Etiology of non-cystic fibrosis bronchiectasis in adults and its correlation to disease severity. Ann Am Thorac Soc 2015;12(12):1764-1770

26 Qi Q, Wang W, Li T, Zhang Y, Li Y. Aetiology and clinical characteristics of patients with bronchiectasis in a Chinese Han population: a prospective study. Respirology 2015;20(06):917-924

27 Guan WJ, Gao YH, Xu G, et al. Aetiology of bronchiectasis in Guangzhou, southern China. Respirology 2015;20(05):739-748

28 Lee JVA, Chotirmall S. Etiology and microbiological profile of bronchiectasis in adults. Am J Respir Crit Care Med 2018;197:A1975

29 Visser SK, Bye PTP, Fox GJ, et al. Australian adults with bronchiectasis: the first report from the Australian Bronchiectasis Registry. Respir Med 2019;155:97-103

30 Dhar R, Singh S, Talwar D, et al. Bronchiectasis in India: results from the European Multicentre Bronchiectasis Audit and Research Collaboration (EMBARC) and Respiratory Research Network of India Registry. Lancet Glob Health 2019;7(09): e1269-e1279

31 Picard C, Bobby Gaspar H, Al-Herz W, et al. International Union of Immunological Societies: 2017 Primary Immunodeficiency Diseases Committee Report on Inborn Errors of Immunity. J Clin Immunol 2018;38(01):96-128

32 Orange JS, Ballow M, Stiehm ER, et al. Use and interpretation of diagnostic vaccination in primary immunodeficiency: a working 
group report of the Basic and Clinical Immunology Interest Section of the American Academy of Allergy, Asthma \& Immunology. J Allergy Clin Immunol 2012;130(3, Suppl):S1-S24

33 Keswani A, Dunn NM, Manzur A, et al. The clinical significance of specific antibody deficiency (SAD) severity in chronic rhinosinusitis (CRS). J Allergy Clin Immunol Pract 2017;5(04):1105-1111

34 Vendrell M, de Gracia J, Rodrigo MJ, et al. Antibody production deficiency with normal IgG levels in bronchiectasis of unknown etiology. Chest 2005;127(01):197-204

35 van Kessel DA, van Velzen-Blad H, van den Bosch JMM, Rijkers GT. Impaired pneumococcal antibody response in bronchiectasis of unknown aetiology. Eur Respir J 2005;25(03):482-489

36 Freeman AF, Olivier KN. Hyper-IgE syndromes and the lung. Clin Chest Med 2016;37(03):557-567

37 Davis SD, Schaller J, Wedgwood RJ. Job's syndrome. Recurrent, "cold", staphylococcal abscesses. Lancet 1966;1(7445):1013-1015

38 Freeman AF, Kleiner DE, Nadiminti H, et al. Causes of death in hyper-IgE syndrome. J Allergy Clin Immunol 2007;119(05): $1234-1240$

39 Freeman AF, Renner ED, Henderson C, et al. Lung parenchyma surgery in autosomal dominant hyper-IgE syndrome. J Clin Immunol 2013;33(05):896-902

40 Biggs CM, Keles S, Chatila TA. DOCK8 deficiency: insights into pathophysiology, clinical features and management. Clin Immunol 2017;181:75-82

41 Su HC, Jing H, Angelus P, Freeman AF. Insights into immunity from clinical and basic science studies of DOCK8 immunodeficiency syndrome. Immunol Rev 2019;287(01):9-19

42 Zhang Q Dove CG, Hor JL, et al. DOCK8 regulates lymphocyte shape integrity for skin antiviral immunity. J Exp Med 2014;211 (13):2549-2566

43 Pillay BA, Avery DT, Smart JM, et al. Hematopoietic stem cell transplant effectively rescues lymphocyte differentiation and function in DOCK8-deficient patients. JCI Insight 2019;5:5

44 Sassi A, Lazaroski S, Wu G, et al. Hypomorphic homozygous mutations in phosphoglucomutase 3 (PGM3) impair immunity and increase serum IgE levels. J Allergy Clin Immunol 2014;133 (05):1410-1419, 1419.e1-1419.e13

45 Zhang Y, Yu X, Ichikawa M, et al. Autosomal recessive phosphoglucomutase 3 (PGM3) mutations link glycosylation defects to atopy, immune deficiency, autoimmunity, and neurocognitive impairment. J Allergy Clin Immunol 2014;133(05):1400-1409, 1409.e1-1409.e5

46 Pacheco-Cuéllar G, Gauthier J, Désilets V, et al. A novel PGM3 mutation is associated with a severe phenotype of bone marrow failure, severe combined immunodeficiency, skeletal dysplasia, and congenital malformations. J Bone Miner Res 2017;32(09): 1853-1859

47 Freeman AF, Milner JD. The child with elevated IgE and infection susceptibility. Curr Allergy Asthma Rep 2020;20(11):65

48 Angulo I, Vadas O, Garçon F, et al. Phosphoinositide 3-kinase $\delta$ gene mutation predisposes to respiratory infection and airway damage. Science 2013;342(6160):866-871

49 Lucas CL, Kuehn HS, Zhao F, et al. Dominant-activating germline mutations in the gene encoding the $\mathrm{PI}(3) \mathrm{K}$ catalytic subunit p110 $\delta$ result in T cell senescence and human immunodeficiency. Nat Immunol 2014;15(01):88-97

50 Lucas CL, Chandra A, Nejentsev S, Condliffe AM, Okkenhaug K. $\mathrm{PI} 3 \mathrm{~K} \delta$ and primary immunodeficiencies. Nat Rev Immunol 2016; 16(11):702-714

51 Michalovich D, Nejentsev S. Activated PI3 kinase delta syndrome: from genetics to therapy. Front Immunol 2018;9:369

52 Elkaim E, Neven B, Bruneau J, et al. Clinical and immunologic phenotype associated with activated phosphoinositide 3-kinase $\delta$ syndrome 2: a cohort study. J Allergy Clin Immunol 2016;138 (01):210-218

53 Coulter TI, Chandra A, Bacon CM, et al. Clinical spectrum and features of activated phosphoinositide 3-kinase $\delta$ syndrome: a large patient cohort study. J Allergy Clin Immunol 2017;139(02): 597-606

54 Bruton OC. Agammaglobulinemia. Pediatrics 1952;9(06):722-728

55 Vetrie D, Vorechovský I, Sideras P, et al. The gene involved in Xlinked agammaglobulinaemia is a member of the Src family of protein-tyrosine kinases. Nature 1993;361(6409):226-233

56 Tsukada S, Saffran DC, Rawlings DJ, et al. Deficient expression of a B cell cytoplasmic tyrosine kinase in human X-linked agammaglobulinemia. Cell 1993;72(02):279-290

57 Winkelstein JA, Marino MC, Lederman HM, et al. X-linked agammaglobulinemia: report on a United States registry of 201 patients. Medicine (Baltimore) 2006;85(04):193-202

58 Shillitoe B, Bangs C, Guzman D, et al. The United Kingdom Primary Immune Deficiency (UKPID) registry 2012 to 2017. Clin Exp Immunol 2018;192(03):284-291

59 Ochs HD, Smith Cl. X-linked agammaglobulinemia. A clinical and molecular analysis. Medicine (Baltimore) 1996;75(06):287-299

60 Plebani A, Soresina A, Rondelli R, et al; Italian Pediatric Group for XLA-AIEOP. Clinical, immunological, and molecular analysis in a large cohort of patients with X-linked agammaglobulinemia: an Italian multicenter study. Clin Immunol 2002;104(03):221-230

61 Bryan BA, Battersby A, Shillitoe BM, et al. Respiratory health and related quality of life in patients with congenital agammaglobulinemia in the Northern Region of the UK. J Clin Immunol 2016;36 (05):472-479

62 Shillitoe B, Gennery A. X-linked agammaglobulinaemia: outcomes in the modern era. Clin Immunol 2017;183:54-62

63 Filipovich AH, Weisdorf D, Pavletic S, et al. National Institutes of Health consensus development project on criteria for clinical trials in chronic graft-versus-host disease: I. Diagnosis and staging working group report. Biol Blood Marrow Transplant 2005;11 (12):945-956

64 Labžentytė V, Zemnickienè S, Danila E, Šileikienė V, Zablockis R, Gruslys V. A fast and fatal course of bronchiectasis: an unusual rare expression of chronic graft versus host disease: a case report. Acta Med Litu 2016;23(01):54-59

65 Phatak TD, Maldjian PD. Progressive bronchiectasis as a manifestation of chronic graft versus host disease following bone marrow transplantation. Radiol Case Rep 2015;3(01):137

66 Bhatia S, Francisco L, Carter A, et al. Late mortality after allogeneic hematopoietic cell transplantation and functional status of longterm survivors: report from the Bone Marrow Transplant Survivor Study. Blood 2007;110(10):3784-3792

67 Hildebrandt GC, Fazekas T, Lawitschka A, et al. Diagnosis and treatment of pulmonary chronic GVHD: report from the consensus conference on clinical practice in chronic GVHD. Bone Marrow Transplant 2011;46(10):1283-1295

68 Couriel D, Carpenter PA, Cutler C, et al. Ancillary therapy and supportive care of chronic graft-versus-host disease: national institutes of health consensus development project on criteria for clinical trials in chronic graft-versus-host disease: V. Ancillary Therapy and Supportive Care Working Group Report. Biol Blood Marrow Transplant 2006;12(04):375-396

69 Bergeron A, Belle A, Chevret S, et al. Combined inhaled steroids and bronchodilatators in obstructive airway disease after allogeneic stem cell transplantation. Bone Marrow Transplant 2007;39 (09):547-553

70 Bashoura L, Gupta S, Jain A, et al. Inhaled corticosteroids stabilize constrictive bronchiolitis after hematopoietic stem cell transplantation. Bone Marrow Transplant 2008;41(01):63-67

71 Sicras-Mainar A, de Abajo FJ, Izquierdo-Alonso JL. Clinical and economic consequences of inhaled corticosteroid doses and particle size in triple inhalation therapy for COPD: real-life study. Int J Chron Obstruct Pulmon Dis 2020;15:3291-3302

72 Andréjak C, Nielsen R, Thomsen VO, Duhaut P, Sørensen HT, Thomsen RW. Chronic respiratory disease, inhaled corticosteroids and risk of non-tuberculous mycobacteriosis. Thorax 2013; 68(03):256-262 
73 Greer M, Berastegui C, Jaksch P, et al. Lung transplantation after allogeneic stem cell transplantation: a pan-European experience. Eur Respir J 2018;51(02):51

74 González D, van der Burg M, García-Sanz R, et al. Immunoglobulin gene rearrangements and the pathogenesis of multiple myeloma. Blood 2007;110(09):3112-3121

75 Hallek M, Shanafelt TD, Eichhorst B. Chronic lymphocytic leukaemia. Lancet 2018;391(10129):1524-1537

76 Yogi S, Yamashiro T, Kamiya H, et al. Thoracic manifestations of adult T-cell leukemia/lymphoma on chest CT: difference between clinical subtypes. Diagn Interv Radiol 2019;25(01):55-61

77 Okada F, Ando Y, Kondo Y, Matsumoto S, Maeda T, Mori H. Thoracic CT findings of adult T-cell leukemia or lymphoma. AJR Am J Roentgenol 2004;182(03):761-767

78 Zaman M, Huissoon A, Buckland M, et al. Clinical and laboratory features of seventy-eight UK patients with Good's syndrome (thymoma and hypogammaglobulinaemia). Clin Exp Immunol 2019;195(01):132-138

79 Iyengar S, Harrison J, Richman P. Relapsed B-CLL/small B-lymphocytic lymphoma presenting as bronchiectasis. Eur J Haematol 2007;79(03):274-275

80 Dragic T, Litwin V, Allaway GP, et al. HIV-1 entry into CD4+ cells is mediated by the chemokine receptor CC-CKR-5. Nature 1996;381 (6584):667-673

81 Quinn TC. Acute primary HIV infection. JAMA 1997;278(01): 58-62

82 Kahn JO, Walker BD. Acute human immunodeficiency virus type 1 infection. N Engl J Med 1998;339(01):33-39
83 Cilloniz C, Torres A, Polverino E, et al. Community-acquired lung respiratory infections in HIV-infected patients: microbial aetiology and outcome. Eur Respir J 2014;43(06):1698-1708

84 Anwar GA, McDonnell MJ, Worthy SA, et al. Phenotyping adults with non-cystic fibrosis bronchiectasis: a prospective observational cohort study. Respir Med 2013;107(07):1001-1007

85 Buscot M, Pottier $\mathrm{H}$, Marquette $\mathrm{CH}$, Leroy S. Phenotyping adults with non-cystic fibrosis bronchiectasis: a 10-year cohort study in a French Regional University Hospital Center. Respiration 2016;92 (01):1-8

86 Berman DM, Mafut D, Djokic B, Scott G, Mitchell C. Risk factors for the development of bronchiectasis in HIV-infected children. Pediatr Pulmonol 2007;42(10):871-875

87 Hensley-McBain T, Klatt NR. The dual role of neutrophils in HIV infection. Curr HIV/AIDS Rep 2018;15(01):1-10

88 Bedi P, Davidson DJ, McHugh BJ, Rossi AG, Hill AT. Blood neutrophils are reprogrammed in bronchiectasis. Am J Respir Crit Care Med 2018;198(07):880-890

89 Giam YH, Shoemark A, Chalmers JD. Neutrophil dysfunction in bronchiectasis: an emerging role for immunometabolism. Eur Respir J 2021:2003157

90 Perez EE, Orange JS, Bonilla F, et al. Update on the use of immunoglobulin in human disease: a review of evidence. J Allergy Clin Immunol 2017;139(3S):S1-S46

91 Lucas M, Lee M, Lortan J, Lopez-Granados E, Misbah S, Chapel H. Infection outcomes in patients with common variable immunodeficiency disorders: relationship to immunoglobulin therapy over 22 years. J Allergy Clin Immunol 2010;125(06):1354-1360 